\title{
Preparation and characterization of $\mathrm{SrBi}_{2} \mathrm{Nb}_{2} \mathrm{O}_{9}$ thin films made by polymeric precursors
}

S. M. Zanetti, E. R. Leite, and E. Longo

Departamento de Quimica-UFSCar, P.O. Box 676, 13560-905 São Carlos, SP, Brazil

\author{
J. A. Varela \\ Instituto de Química-UNESP, P.O. Box 355, 14801-970 Araraquara, SP, Brazil
}

(Received 24 September 1997; accepted 20 May 1998)

A polymeric precursor solution was employed in preparing $\mathrm{SrBi}_{2} \mathrm{Nb}_{2} \mathrm{O}_{9}(\mathrm{SBN})$ powder and thin films dip coated onto $\mathrm{Si}(100)$ substrate. XRD results show that the SBN perovskite phase forms at temperatures as low as $600{ }^{\circ} \mathrm{C}$ through an intermediate fluorite phase. This fluorite phase is observed for samples heat-treated at temperatures of 400 and $500{ }^{\circ} \mathrm{C}$. After heat treatment at temperatures ranging from 300 to $800{ }^{\circ} \mathrm{C}$, thin films were shown to be crack free. Grazing incident angle XRD characterization shows the occurrence of the fluorite intermediate phase for films also. The thickness of films, measured by MEV, was in the order of $80-100 \mathrm{~nm}$.

\section{INTRODUCTION}

Recently, ferroelectric thin films for nonvolatile memory applications have attracted great interest. In particular, those ferroelectric materials belonging to the layered perovskite family, such as $\mathrm{SrBi}_{4} \mathrm{Ti}_{4} \mathrm{O}_{15}$ (SBIT), $\mathrm{SrBi}_{2} \mathrm{Ta}_{2} \mathrm{O}_{9}$ (SBT), and $\mathrm{SrBi}_{2} \mathrm{Nb}_{2} \mathrm{O}_{9}(\mathrm{SBN})$, due to their nonfatigue nature and the possibility of low polarization switching voltage, which were major drawbacks for other materials such as lead zirconate titanate (PZT). ${ }^{1,2}$

Several deposition techniques have been used to obtain thin films of these compounds, such as pulsed laser ablation, ${ }^{3-5}$ chemical vapor deposition (CVD) ${ }^{6,7}$ metallorganic decomposition (MOD), ${ }^{8,9}$ and sol-gel. ${ }^{10,11}$ However, these methods require heat treatment at high temperatures, what is seriously deleterious to the $\mathrm{Si}$ wafer properties.

In this paper, we report the preparation of SBN thin films by the polymeric precursor method, dip coated onto $\mathrm{Si}(100)$ and $\mathrm{Pt} / \mathrm{Ti} / \mathrm{SiO}_{2} / \mathrm{Si}(100)$. The polymeric precursor method was proposed by Pechini ${ }^{12}$ and has been widely utilized to synthesize mixed oxides. The advantage of this method is the possibility of precise stoichiometric control, besides utilization of simple and cheaper reagents as precursors. ${ }^{13,14}$ As far as we know, no polymeric precursor solutions have been reported for SBN production.

\section{EXPERIMENTAL}

Strontium carbonate, $\mathrm{SrCO}_{3}$ (Merck), niobium ammonium oxalate, $\mathrm{NH}_{4} \mathrm{H}_{2}\left[\mathrm{NbO}\left(\mathrm{C}_{2} \mathrm{O}_{4}\right)_{3}\right] \cdot 3 \mathrm{H}_{2} \mathrm{O}$ (CBMM, Araxá, Brazil), and bismuth oxide, $\mathrm{Bi}_{2} \mathrm{O}_{3}$ (Aldrich) were used as reagents to synthesize $\mathrm{SrBi}_{2} \mathrm{Nb}_{2} \mathrm{O}_{9}(\mathrm{SBN})$. Niobium hydroxide was formed by dissolution of the niobium ammonium oxalate in water and precipitated as
$\mathrm{Nb}(\mathrm{OH})_{5}$ by addition of $\mathrm{NH}_{4} \mathrm{OH}$. After filtration, niobium hydroxide was dissolved in an aqueous solution of citric acid to form niobium citrate. The content of $\mathrm{Nb}$ was gravimetrically determined as $\mathrm{Nb}_{2} \mathrm{O}_{5}$. To this niobium citrate solution were added stoichiometric amounts of $\mathrm{SrCO}_{3}$ as salt and $\mathrm{Bi}_{2} \mathrm{O}_{3}$ dissolved in water with $\mathrm{HNO}_{3}$. Ethylenediamine was added dropwise into the solution with constant stirring until the $\mathrm{pH}$ reached 7-8. After homogenization of the solution, ethylene glycol was added to promote polymerization of mixed citrate by polyestherification reaction. The molar ratio among strontium, bismuth, and niobium was $1: 2: 2$, the citric acid/metal molar ratio was fixed at 3.95 , and the citric acid/ethylene glycol ratio was fixed as 60/40 (mass ratio). Figure 1 shows a flowchart for preparing $\mathrm{SrBi}_{2} \mathrm{Nb}_{2} \mathrm{O}_{9}$ precursor solution. This solution was used for direct deposition of thin film, and after partial decomposition of the organic polymer, to prepare the SBN powder. Partially decomposed solid resin was ground in a mortar and calcined at temperatures ranging from 400 to $800{ }^{\circ} \mathrm{C}$ for $2 \mathrm{~h}$.

Prior to coating, the substrates were cleaned by immersion in a sulfochromic solution followed by rinsing several times in de-ionized water. The dip coating was conducted by immersion of the clean substrates in the polymeric solution followed by controlled withdrawal at a speed of $1 \mathrm{~cm} / \mathrm{min}$. After deposition, substrates were dried on a hot plate $\left(\sim 150{ }^{\circ} \mathrm{C}\right)$ followed by a twostep heat treatment. In this first step, the temperature was raised to $300{ }^{\circ} \mathrm{C}$ and kept at this temperature for $2 \mathrm{~h}$, for elimination of the organic material. In a second step, films were heat-treated at the desired temperature and soaked for $2 \mathrm{~h}$ at temperatures ranging from 300 to $800{ }^{\circ} \mathrm{C}$. Heating and cooling rates were $1{ }^{\circ} \mathrm{C} / \mathrm{min}$. The polymeric precursor solution viscosity was adjusted by 


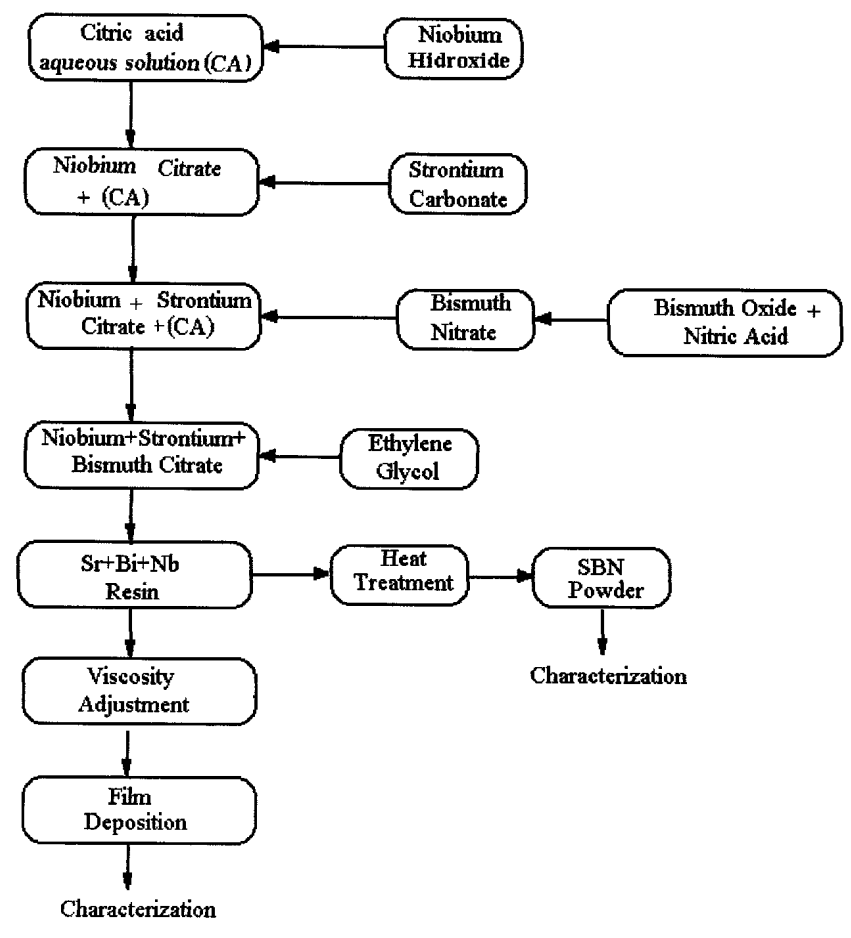

FIG. 1. Flowchart of polymeric precursor preparation.

adding water to the polymeric solution and measured using a viscometer (Brookfield, DV-III) at $25{ }^{\circ} \mathrm{C}$ until a value of $14 \mathrm{mPa} \cdot \mathrm{s}$ was reached. The $(\mathrm{Sr}, \mathrm{Bi}, \mathrm{Nb})$ polymeric precursor was characterized by simultaneous thermal analysis, TG/DTA (Netzsch, STA409), in synthetic air $\left(50 \mathrm{~cm}^{3} / \mathrm{min}\right)$ using a constant heating rate of $5{ }^{\circ} \mathrm{C} / \mathrm{min}$ from room temperature to $1000{ }^{\circ} \mathrm{C}$. The powder calcined at different temperatures was characterized by x-ray diffraction (XRD) (Siemens, D5000) with $\mathrm{CuK}_{\alpha}$ radiation and a graphite monochromator. The lattice parameters were measured using the leastsquares method, using $\mathrm{SiO}_{2}$ as standard. The phase evolution of films was followed by grazing incident $\mathrm{x}$-ray diffraction (GIXRD) (Siemens, D5000), using an incident angle of $2^{\circ}(\theta)$ and a $\operatorname{LiF}(100)$ monochromator. The microstructure evolution and thickness were characterized by a scanning electron microscope (SEM) (Zeiss, DSM940A).

The thermogravimetric results showed weight loss in several temperature ranges for the polymeric precursor. For temperatures higher than $580{ }^{\circ} \mathrm{C}$, no more weight loss was observed. Figure 2 shows DTA results of the polymeric precursor powder heat-treated at $400{ }^{\circ} \mathrm{C}$ for $2 \mathrm{~h}$. A broad exothermic peak centered at $521{ }^{\circ} \mathrm{C}$, related to an intermediate phase crystallization phenomenon, followed by a small endothermic peak at $620{ }^{\circ} \mathrm{C}$, probably related to the perovskite SBN phase formation, was observed.

Figure 3 shows the phase evolution characterized by XRD. The powder sample heat-treated at $300{ }^{\circ} \mathrm{C}$ shows

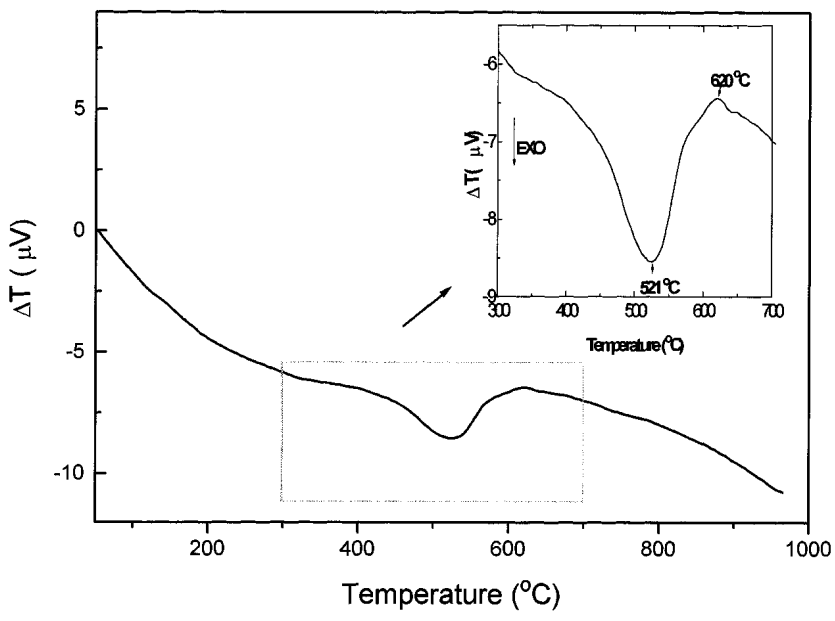

FIG. 2. DTA curve of polymeric precursor heat-treated at $400{ }^{\circ} \mathrm{C}$ for $2 \mathrm{~h}$.

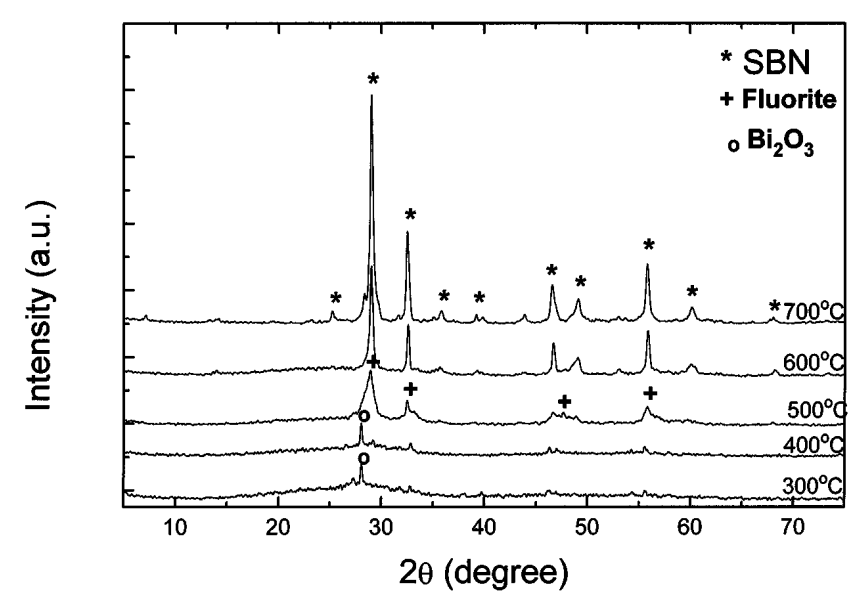

FIG. 3. XRD results for powder samples heat-treated at 300, 400, 500,600 , and $700{ }^{\circ} \mathrm{C}$ for $2 \mathrm{~h}$.

a poorly crystallized $\mathrm{Bi}_{2} \mathrm{O}_{3}$ phase. As the temperature increased, this $\mathrm{Bi}_{2} \mathrm{O}_{3}$ phase originated a nonindexed phase. This phase is likely related to an intermediate fluorite phase. As observed in the XRD pattern (Fig. 3), the perovskite phase (SBN) originates from this fluorite phase, as observed by Boyle et al. for $\mathrm{SrBi}_{2} \mathrm{Ta}_{2} \mathrm{O}_{9}$ (SBT). ${ }^{15,16}$ These results suggest that the peak observed by DTA at $521{ }^{\circ} \mathrm{C}$ is due to the fluorite phase crystallization. Lattice parameters measured for the SBN phase calcined at $1000{ }^{\circ} \mathrm{C}$ for $2 \mathrm{~h}$ showed $a=$ $b=5.507 \AA$ and $c=25.05 \AA$ values. These values are in agreement with those reported by Subbarao ${ }^{17}$ if considered a tetragonal structure.

Figure 4 shows the phase evolution characterized for films using GIXRD. In contrast to results shown for powder samples, a diffuse XRD pattern is observed for films heat-treated at 300 and $400{ }^{\circ} \mathrm{C}$, indicating that the precursor is amorphous. Films heat-treated at 500 and $600{ }^{\circ} \mathrm{C}$ presented the fluorite phase, in agreement 


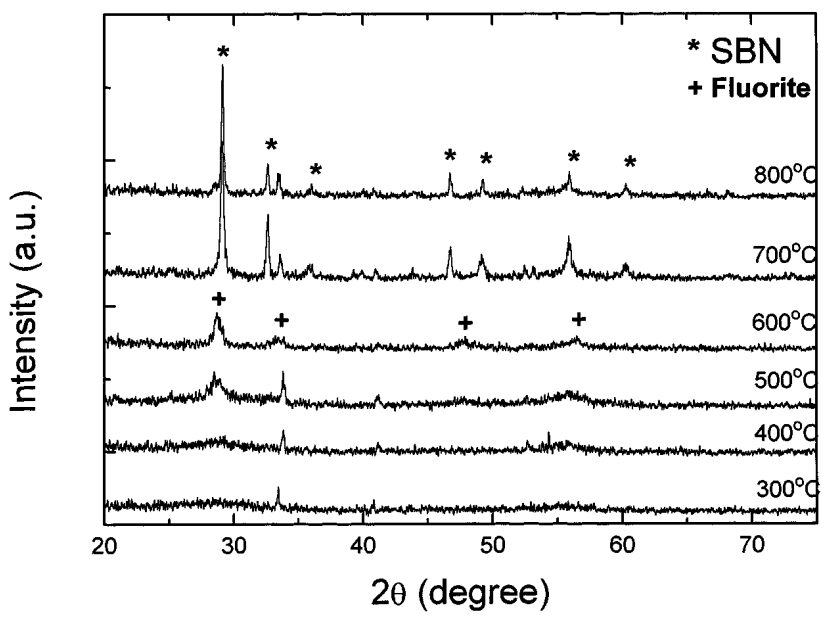

FIG. 4. GIXRD results for films heat-treated at 300, 400, 500, 600, 700 , and $800{ }^{\circ} \mathrm{C}$ for $2 \mathrm{~h}$.

with results obtained for powder samples. After thermal treatment at $700{ }^{\circ} \mathrm{C}$, only peaks related to the SBN phase are observed. These results suggest that the SBN phase is formed at temperatures between 600 and $700{ }^{\circ} \mathrm{C}$. Lattice parameters calculated for films heat-treated at $800{ }^{\circ} \mathrm{C}$ for $2 \mathrm{~h}$ were $a=b=5.497 \AA$ and $c=24.01 \AA$. These results are different from those obtained for the powder; in films, the $c$ parameter is smaller, indicating, probably, diffusion and reaction between film and silicon wafer or compression stress.

Crack-free films with an area of $1.0 \times 1.0 \mathrm{~cm}$ were obtained after heat treatment at several temperatures. The scanning electron micrograph of Fig. 5 shows a microstructure evolution as a function of heat-treatment temperature. Films heat-treated at $600{ }^{\circ} \mathrm{C}$ [Fig. 5(a)] are crack free, with a smooth surface and no defined grain structure. A defined grain structure can be observed for films heat-treated at $700{ }^{\circ} \mathrm{C}$ [Fig. 5(b)]. Thickness, evaluated by SEM, ranged from 80 to $100 \mathrm{~nm}$.

Figure 6 presents the SBN film deposited onto $\mathrm{Pt} / \mathrm{Ti} / \mathrm{SiO}_{2} / \mathrm{Si}(100)$ substrate. It can be observed that the XRD data [Fig. 6(a)] show a monophasic film, with a preferential orientation in the $\langle 215\rangle$ direction and a homogeneous and dense microstructure [Fig. 6(b)], with well-defined spherical type grains. Electrical measurements of films deposited onto Pt are in progress.

\section{CONCLUSIONS}

Polymeric precursors method allows one to synthesize $\mathrm{SrBi}_{2} \mathrm{Nb}_{2} \mathrm{O}_{9}(\mathrm{SBN})$ phase at temperatures as low as $600{ }^{\circ} \mathrm{C}$. This is an improvement in the synthesis of this compound once the traditional solid state reaction requires temperatures above $1200{ }^{\circ} \mathrm{C}$. XRD data show that the SBN perovskite phase crystallizes through an intermediate fluorite phase. The experimental results show that crack-free SBN thin films can be formed
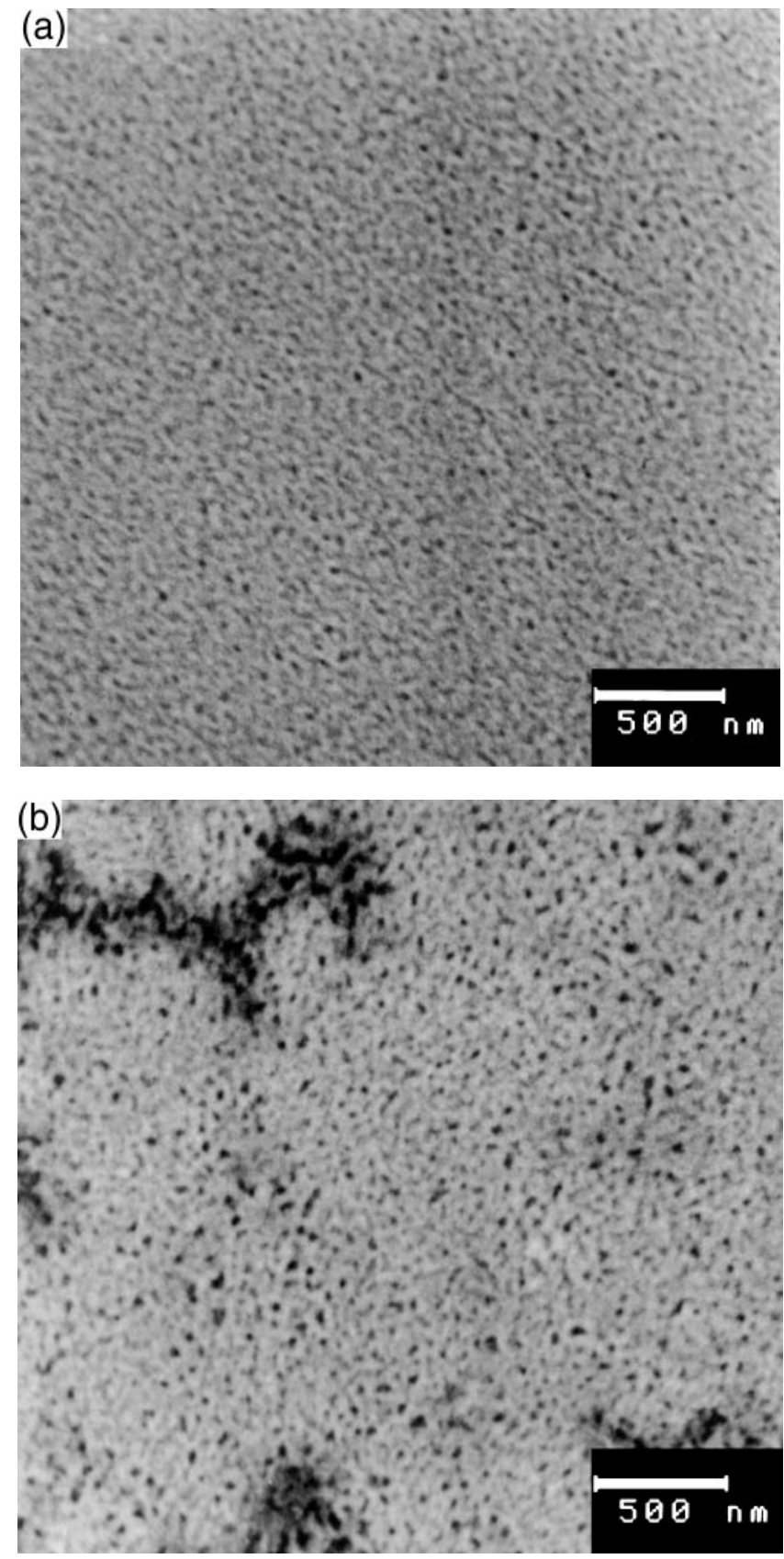

FIG. 5. Set of SEM micrographs for films with different heat treatments: (a) $600{ }^{\circ} \mathrm{C}$ and (b) $700{ }^{\circ} \mathrm{C}$.

by dip coating onto $\mathrm{Si}(100)$ substrate using polymeric precursors method. The SBN phase crystallizes at temperatures between 600 and $700{ }^{\circ} \mathrm{C}$ in films.

\section{ACKNOWLEDGMENTS}

The authors acknowledge the following Brazilian financing support agencies: FAPESP (Projects 96/ 10118-1 and 96/9748-0), CNPq, and FINEP/PRONEX, and CBMM-Companhia Brasileira de Metalurgia e Mineração. 

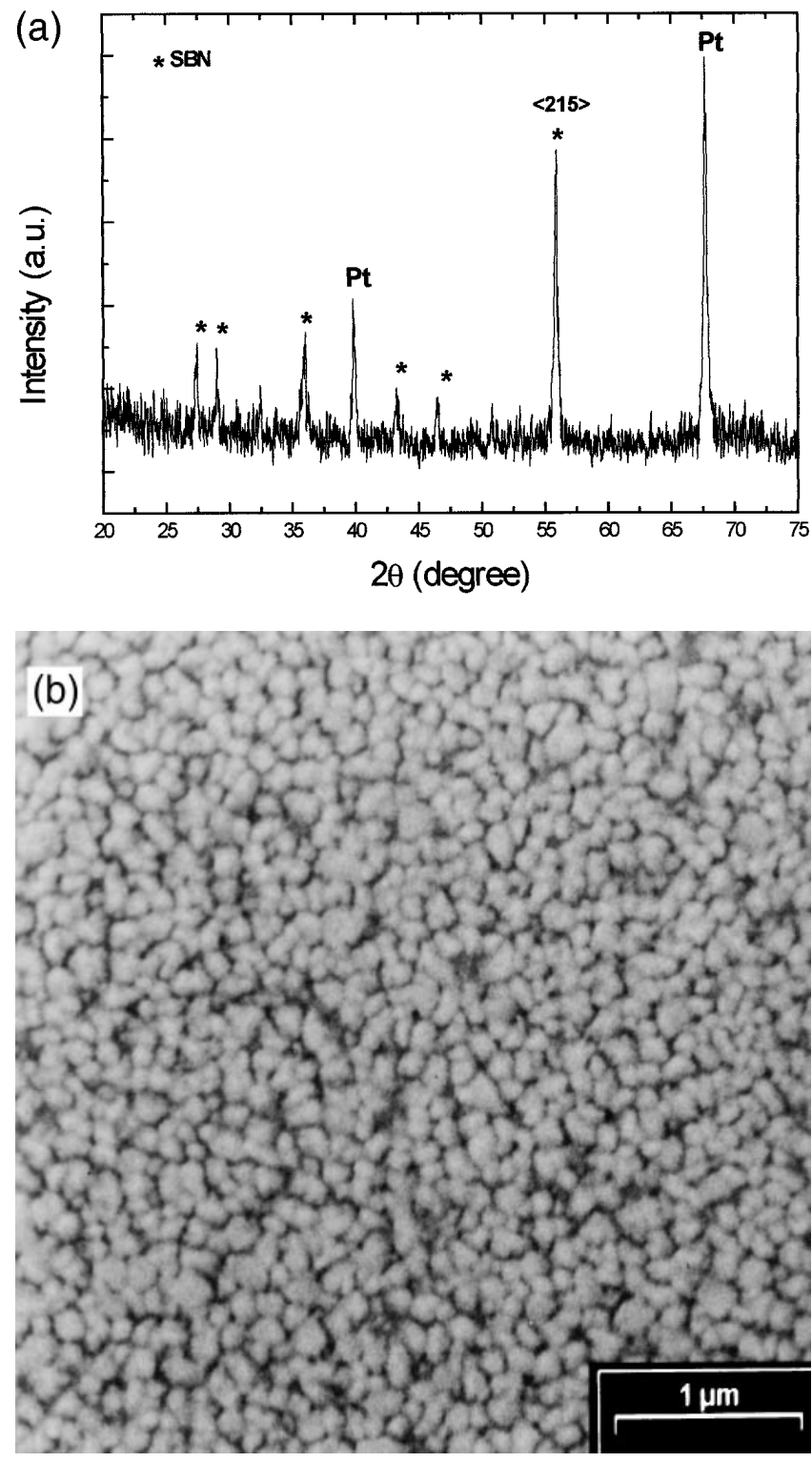

FIG. 6. SBN film deposited onto $\mathrm{Pt} / \mathrm{Ti} / \mathrm{SiO}_{2} / \mathrm{Si}(100)$ heat-treated at $700{ }^{\circ} \mathrm{C}$. (a) GIXRD result; (b) SEM micrograph.

\section{REFERENCES}

1. Y. Ito, M. Ushikubo, S. Yokoyama, H. Matsunaga, T. Atsuki, T. Yonezawa, and K. Ogi, Jpn. J. Appl. Phys. 35, 4925 (1996).

2. T. Noguchi, T. Hase, and Y. Miyasaka, Jpn. J. Appl. Phys. 35, 4900 (1996).

3. Y. Oishi, W. Wu, K. Fumoto, M. Okuyama, and Y. Hamakawa, Jpn. J. Appl. Phys. 35, 1242 (1996).

4. L. Dat, J. K. Lee, O. Auciello, and A. I. Kingon, Appl. Phys. Lett. 67, 572 (1995).

5. H. Tabata, H. Tanaka, and T. Kawai, Jpn. J. Appl. Phys. 34, 5146 (1995).

6. Y. Zhu, S. B. Desu, T. Li, S. Ramanathan, and M. Nagata, J. Mater. Res. 12, 783 (1997).

7. T. Li, Y. Zhu, and S. B. Desu, J. Appl. Phys. 68, 5 (1996).

8. H. Watanabe, T. Mihara, H. Yoshimori, and C. A. P. Araujo, Jpn. J. Appl. Phys. 34, 5240 (1995).

9. P. Y. Chu, R. E. Jones, Jr., P. Zurcher, D. J. Taylor, B. Jiang, S. J. Gillespie, Y. T. Lii, M. Kottke, P. Fejes, and W. Chen, J. Mater. Res. 11, 1065 (1996).

10. H. N. Al-Shareef, D. Dimos, T. J. Boyle, W. L. Warren, and B. A. Tuttle, Appl. Phys. Lett. 68 (5), 690 (1996).

11. T. Atsuki, N. Soyama, T. Yonezawa, and K. Ogi, Jpn. J. Appl. Phys. 34, 5096 (1995).

12. M.P. Pechini, U.S. Patent 3,330,697 (1967).

13. V. Bouquet, S. M. Zanetti, C. R. Foschini, E. R. Leite, E. Longo, and J. A. Varela, Ceram. Trans. (1997).

14. S. M. Zanetti, E. Longo, J. A. Varela, and E. R. Leite, Mater. Lett. 31, 173 (1997).

15. T. J. Boyle, C.D. Buchheit, M. A. Rodriguez, H. N. Al-Shareef, B. A. Hernandez, B. Scott, and J. W. Ziller, J. Mater. Res. 11, 2274 (1996).

16. M. A. Rodriguez, T. J. Boyle, B. A. Hernandez, C. D. Buchheit, and M. O. Eatough, J. Mater. Res. 11, 2282 (1996).

17. E. C. Subbarao, J. Phys. Chem. Solids 23, 665 (1992). 